\title{
Correlation between serum homocysteine level and ulcerative colitis: A meta-analysis
}

https://doi.org/10.1515/pteridines-2019-0013

received December 4, 2018; accepted April 19, 2019.

Abstract: Background: The aim of the present metaanalysis was to investigate the correlation of serum homocysteine (Hcy) concentration and ulcerative colitis (UC) through pooling all the relevant publications.

Methods The electronic databases of PubMed, EMBase, Web of Science, Google Scholar, CBM, and CNKI were systematic searched with the text words of homocysteine/Hcy, ulcerative colitis/UC, and inflammatory bowel disease. The correlation between serum Hcy and UC were demonstrated by stand mean difference (SMD) and corresponding 95\% confidence interval (95\% CI). The publication bias was evaluated by Egger's line regression test and Begg's funnel plot.

Results After systematic searching the related electronic databases of PubMed, EMBase, Web of Science, Google Scholar, CBM, and CNKI, eighteen publications relevant to serum Hcy and UC were included in the present meta-analysis. The serum Hcy leves were $14.01 \pm 2.76$ and $10.31 \pm 1.59 \mu \mathrm{mol} / \mathrm{L}$ for UC groups and healthy controls respectively with statistical difference $(\mathrm{p}<0.05)$. Significant heterogeneity was found $\left(\mathrm{I}^{2}=94.5 \%\right.$, $\mathrm{p}<0.001)$ among the included studies. Therefore, the SMD was pooled through the random effect model. The pooled SMD was 1.20 (95\% CI: 0.89-1.51), indicating that serum Hcy levels were significant higher in UC groups compared to healthy controls with statistical difference $(\mathrm{Z}=7.52, \mathrm{P}<0.001)$. Egger's line regression test indicated no publications bias $(\mathrm{t}=1.45, \mathrm{p}=0.17)$.

Conclusion: Serum Hcy levels were usually elevated in UC patients, which indicates that Hcy may play an

\footnotetext{
*Corresponding author: Fang Fang, Department of Clinical Laboratory, Hangzhou Xiaoshan District Third People‘s Hospital, Xiaoshan District , Hangzhou City Zhejiang Province 311251 PR China, E-mail: 1433051569@qq.com Yifang Zhong, Feng Yan, Weixia Jie, Ying Zhou: Department of Clinical Laboratory, Lishui People's Hospital, 6th Affiliated Hospital of Wenzhou Medical University, Lishui Zhejiang Province 323000 PR China
}

important role in UC development and may be used as a serological biomarker for UC diagnosis.

Keywords: Homocysteine; ulcerative colitis; metaanalysis; diagnosis.

\section{Introduction}

Homocysteine (Hcy), a sulfur-containing amino acid, is a product of methionine. Generally, homocysteine maintains a low level in serum in the human body under normal physiological conditions. Abnormally high levels of homocysteine in the serum, above $15 \mu \mathrm{mol} / \mathrm{L}$, is a medical condition called hyperhomocysteinemia [1]. Hyperhomocysteinemia was considered to be a significant risk factor for the development of a wide range of diseases, including thrombosis $[2,3]$, neuropsychiatric illness $[4,5]$, and fractures [6, 7]. Hyperhomocysteinemia is also found to be associated with microalbuminuria, which is a strong indicator of the risk of developing renal dysfunction $[8,9]$. Recently, several studies have reported the elevated serum Hcy in UC patients compared to healthy controls [10, 11]. A meta-analysis has also evaluated the genetic variants of homocysteine/folate metabolism pathway and risk of inflammatory bowel disease [12]. However, meta-analysis relevant to serum Hcy concentration and ulcerative colitis was not discussed in the previous literature.

\section{Material And Methods}

\section{Publications searching in the electronic databases}

The electronic databases of PubMed, Embase, Web of Science, Google Scholar, CBM, and CNKI were systematic searched with the text words of homocysteine/Hcy, ulcerative colitis/UC, and inflammatory bowel disease. The publication inclusion criteria were (i) the publication type was a case-control or cohort study, (ii) the published 
language was English or Chinese, (iii) UC was confirmed in the case group, and (iv) serum Hcy levels in UC patients and healthy controls can be extracted from the original studies. The publication exclusion criteria were (i) other study types such as case report or review, (ii) inflammatory bowel disease other than UC, and (iii) duplicated published data or studies.

\section{Publication review and data extraction from each of the included study}

The full text of the studies included in the meta-analysis were reviewed by two reviewers (Yifang Zhong \& Feng Yan) independently. The general information and important data were extracted from each of the original publication. The information included (i) the first and corresponding authors of the included studies, (ii) the sample size, (iii) the country of study performed, (iv) the age of the UC group and healthy controls, (v) serum Hcy concentration examination methods, (vi) the quality of each included study (NOS score), and (vii) the serum level of Hcy of each original study.

\section{Quality evaluation of each study}

The general quality of the included eighteen studies was evaluated by Newcastle-Ottawa scale (NOS) [13]. The NOS ranges from 0 to 9 stars and the more stars the higher quality of the included case or cohort study.

\section{Statistical analysis}

All the data was analyzed by Stata10.0 SE software. The correlation between serum Hcy level and ulcerative colitis was expressed by stand mean difference (SMD). Before pooling the data, we fist evaluated the statistical heterogeneity across the included studies by $\mathrm{I}^{2}$ test ( $\mathrm{I}^{2}>50 \%$, random effect model; $\mathrm{I}^{2}<=50 \%$, fixed effect model), and then pooled the SMD by a fixed or random effect model.. The publication bias was evaluated through a Begg's funnel plot and Egger's test. Two tails $p<0.05$ was considered statistical significant.

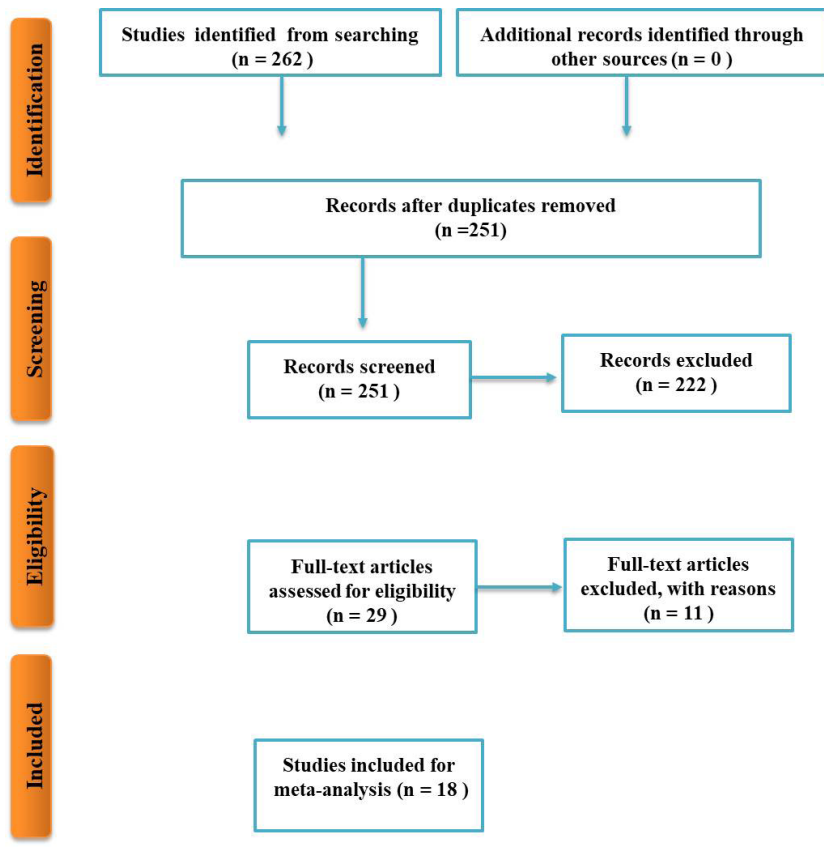

Figure 1: The publication screen flow chart in the electronic databases.

\section{Results}

\section{Main features of the included publications}

After systematic searching the related electronic databases, eighteen publications relevant to serum Hcy and UC were finally included in the present meta-analysis. The publication electronic searching procedure is shown in Figure 1. The general features of the included eighteen publications are demonstrated in Table 1. Sample sizes ranged from 51 to 1063 subjects. The serum Hcy levels ranged from 10.10 to $20.67 \mu \mathrm{mol} / \mathrm{L}$ for UC groups and 6.80 to $13.21 \mu \mathrm{mol} / \mathrm{L}$ for control groups. The NOS score, which was used for evaluation the quality of the case-control studies, ranged from 4 to 6 .

\section{Serum Hcy concentration in UC and healthy controls}

The serum Hcy levels were $14.01 \pm 2.76$ and $10.31 \pm 1.59 \mu \mathrm{mol} / \mathrm{L}$ for UC group and healthy controls respectively. The serum Hcy concentration of UC group was significantly higher than that of controls with statistical difference $(p<0.05)$, Figure 2. 
Table 1: Main features of the included eighteen publications.

\begin{tabular}{|c|c|c|c|c|c|c|c|c|c|}
\hline \multirow{2}{*}{$\begin{array}{l}\begin{array}{l}\text { Author } \\
\text { (Year) }\end{array} \\
\end{array}$} & \multirow[t]{2}{*}{ Region } & \multicolumn{2}{|c|}{ Sample size } & \multicolumn{2}{|l|}{ Age } & \multicolumn{2}{|c|}{ Hcy level $(\mu \mathrm{mol} / \mathrm{L})$} & \multirow[t]{2}{*}{ Methods } & \multirow{2}{*}{$\begin{array}{l}\text { NOS } \\
\text { score }\end{array}$} \\
\hline & & UC & Control & UC & Control & UC & Control & & \\
\hline $\begin{array}{l}\text { Danese (2005) } \\
\text { [10] }\end{array}$ & Italy & 83 & 70 & NA & NA & $11.1 \pm 4.9$ & $7.1 \pm 1.7$ & HPLC & 6 \\
\hline $\begin{array}{l}\text { Drzewoski J } \\
(2006)[11]\end{array}$ & Greece & 30 & 21 & $50.3 \pm 11.7$ & $53.1 \pm 12.8$ & $10.1 \pm 3.1$ & $6.8 \pm 2.5$ & HPLC & 6 \\
\hline $\begin{array}{l}\text { Jiang Y (2010) } \\
\text { [14] }\end{array}$ & China & 299 & 764 & NA & NA & $20.67 \pm 6.42$ & $13.21 \pm 5.11$ & $\begin{array}{l}\text { Enzymatic cycling } \\
\text { method }\end{array}$ & 4 \\
\hline $\begin{array}{l}\text { Akbulut S (2010) } \\
\text { [15] }\end{array}$ & Turkey & 55 & 45 & $47.4 \pm 13.8$ & $46.4 \pm 13.8$ & $13.3 \pm 1.93$ & $11.2 \pm 3.8$ & HPLC & 6 \\
\hline $\begin{array}{l}\text { Chen ML (2012) } \\
\text { [16] }\end{array}$ & China & 112 & 110 & $39.4 \pm 11.7$ & $40.3 \pm 10.8$ & $11.27 \pm 7.26$ & $8.19 \pm 4.81$ & HPLC & 5 \\
\hline $\begin{array}{l}\text { Sun J (2012) } \\
\text { [17] }\end{array}$ & China & 60 & 20 & NA & NA & $14.67 \pm 6.77$ & $11.16 \pm 2.67$ & Chemiluminescence & 5 \\
\hline Ni Z (2013) [18] & China & 52 & 50 & $47.4 \pm 13.8$ & $46.4 \pm 13.89$ & $13.70 \pm 1.92$ & $11.10 \pm 3.85$ & $\begin{array}{l}\text { Enzymatic cycling } \\
\text { method }\end{array}$ & 4 \\
\hline $\begin{array}{l}\text { Wang JJ (2014) } \\
\text { [19] }\end{array}$ & China & 68 & 60 & $45.8 \pm 12.7$ & NA & $14.90 \pm 5.39$ & $11.38 \pm 4.39$ & Chemiluminescence & 4 \\
\hline $\begin{array}{l}\text { Liu SL (2014) } \\
\text { [20] }\end{array}$ & China & 50 & 50 & $46.7 \pm 13.2$ & $46.3 \pm 13.9$ & $13.73 \pm 1.91$ & $11.24 \pm 3.85$ & $\begin{array}{l}\text { Enzymatic cycling } \\
\text { method }\end{array}$ & 5 \\
\hline $\begin{array}{l}\text { Ju HY (2014) } \\
\text { [21] }\end{array}$ & China & 60 & 60 & $58.12 \pm 7.49$ & $68.29 \pm 7.33$ & $14.74 \pm 1.91$ & $10.26 \pm 1.48$ & $\begin{array}{l}\text { Enzymatic cycling } \\
\text { method }\end{array}$ & 5 \\
\hline $\begin{array}{l}\text { Dnauta O (2014) } \\
\text { [22] }\end{array}$ & & 47 & 65 & $37.94 \pm 13.44$ & $34.38 \pm 12.12$ & $10.34 \pm 4.31$ & $9.71 \pm 2.81$ & $\begin{array}{l}\text { fluorescent traceing } \\
\text { assay }\end{array}$ & 6 \\
\hline $\begin{array}{l}\text { Chen SW (2015) } \\
\text { [23] }\end{array}$ & China & 100 & 100 & $61.37 \pm 8.24$ & $67.53 \pm 6.87$ & $15.02 \pm 1.70$ & $10.19 \pm 1.53$ & $\begin{array}{l}\text { Enzymatic cycling } \\
\text { method }\end{array}$ & 4 \\
\hline $\begin{array}{l}\text { Zhou XJ (2015) } \\
\text { [24] }\end{array}$ & China & 60 & 55 & $47.0 \pm 12.8$ & $49.0 \pm 10.8$ & $18.60 \pm 2.90$ & $10.50 \pm 4.304$ & $\begin{array}{l}\text { Enzymatic cycling } \\
\text { method }\end{array}$ & 5 \\
\hline $\begin{array}{l}\text { Yang J (2016) } \\
\text { [25] }\end{array}$ & China & 64 & 32 & NA & NA & $13.78 \pm 1.91$ & $11.16 \pm 1.46$ & $\begin{array}{l}\text { Fluorescence } \\
\text { polarization }\end{array}$ & 5 \\
\hline $\begin{array}{l}\text { Zhuo XJ (2016) } \\
\text { [26] }\end{array}$ & China & 84 & 30 & $42.15 \pm 9.84$ & $40.83 \pm$ & $14.28 \pm 1.21$ & $11.16 \pm 1.46$ & Immunoturbidimetry & 5 \\
\hline $\begin{array}{l}\text { Xue XY (2017) } \\
\text { [27] }\end{array}$ & China & 112 & 100 & $41.13 \pm 9.14$ & $41.79 \pm 8.95$ & $16.93 \pm 9.49$ & $10.33 \pm 7.48$ & $\begin{array}{l}\text { Enzymatic cycling } \\
\text { method }\end{array}$ & 4 \\
\hline $\begin{array}{l}\text { Zheng SZ (2017) } \\
\text { [28] }\end{array}$ & China & 397 & 574 & $41.30 \pm 11.50$ & $40.30 \pm 8.70$ & $11.38 \pm 3.46$ & $9.65 \pm 2.94$ & $\begin{array}{l}\text { Enzymatic cycling } \\
\text { method }\end{array}$ & 6 \\
\hline Liu C (2018) [29] & China & 63 & 63 & $41.7 \pm 6.0$ & $46.6 \pm 6.1$ & $13.74 \pm 1.90$ & $11.23 \pm 3.57$ & $\begin{array}{l}\text { Enzymatic cycling } \\
\text { method }\end{array}$ & 4 \\
\hline
\end{tabular}

NOS: Newcastle-Ottawa scale

HPLC: High-performance liquid chromatography 


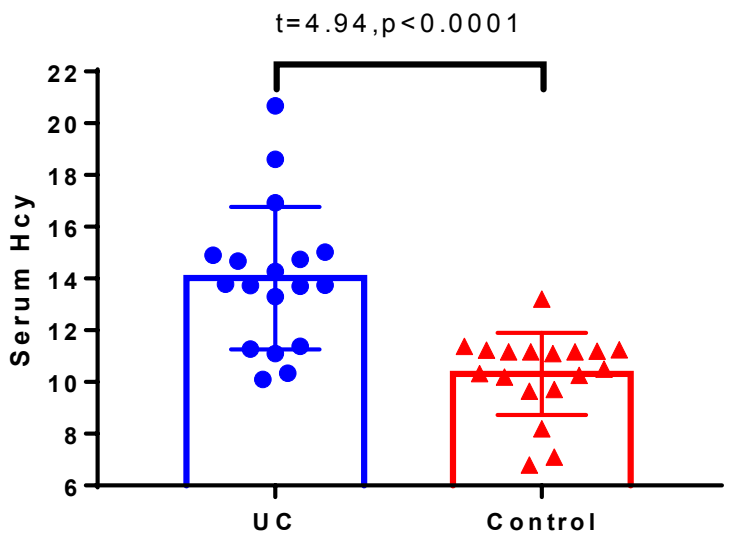

Figure 2: The scatter plot of serum Hcy level distribution of each included publications between UC and controls groups.

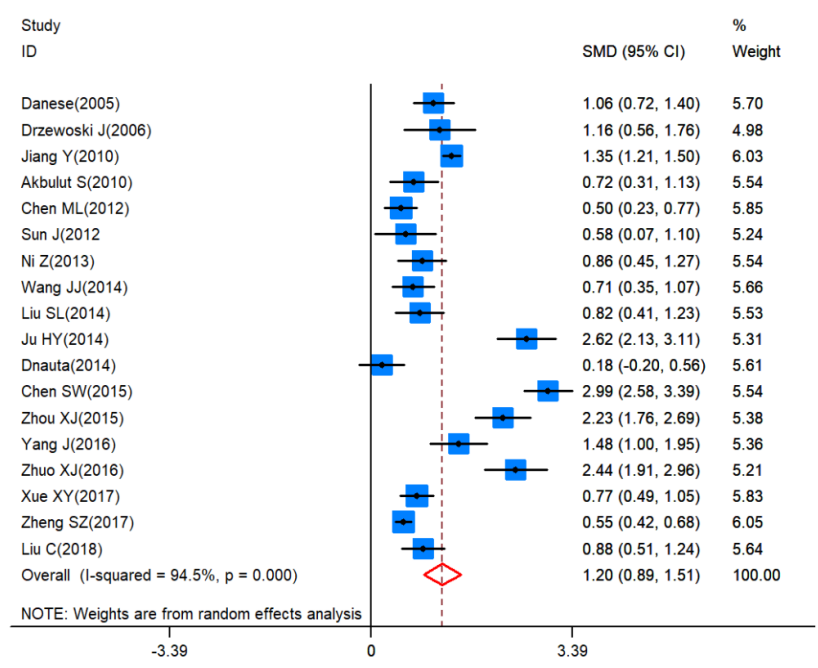

Figure 3: Forrest plot of serum Hcy levels between UC patients and healthy controls. The squares and horizontal lines demonstrate the study-specific SMD and $95 \% \mathrm{Cl}$. The area of the squares reflects the study specific weight. The diamond represents the pooled OR and $95 \% \mathrm{Cl}$.

\section{Meta-analysis}

Before pooling the data, we first evaluated the statistical heterogeneity across the included eighteen publications. Significant heterogeneity was found $\left(I^{2}=94.5 \%, p<0.001\right)$ among the included studies. Therefore, the SMD were pooled through the random effect model. The pooled SMD was 1.20 (95\% CI:0.89-1.51) indicating serum Hcy levels were significantly higher in UC group compared to healthy controls with statistical difference $(\mathrm{Z}=7.52, \mathrm{P}<0.001)$, Figure3.

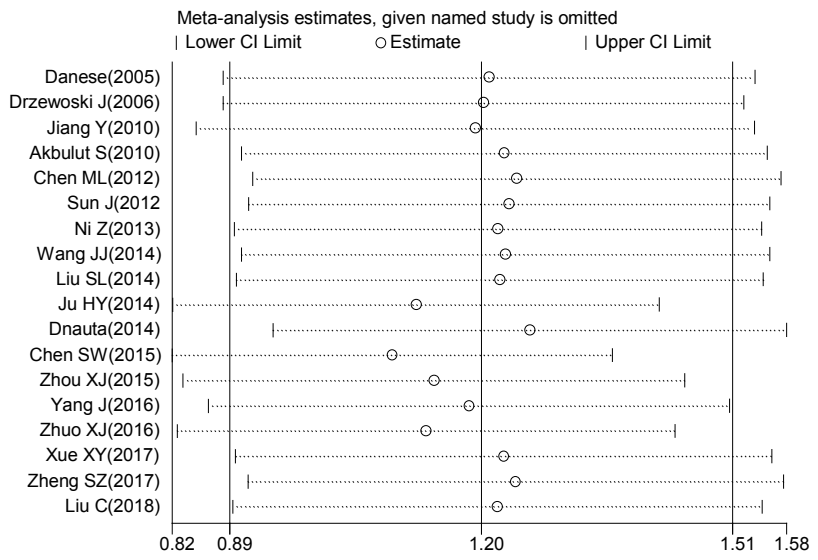

Figure 4: Forest plot of SMD by omitting each of the included publications. The circle and horizontal lines demonstrate the studyspecific SMD and confidence interval by omitting the corresponding study.

\section{Sensitivity analysis}

Sensitivity analysis was performed by omitting each of the included publications. The pooled SMD changed from 0.93 (95\% CI: 0.86-1.00) to 1.17 (95\% CI: 1.09-1.25) by omitting each of the included studies, Table 2 . This indicates that the pooled SMD were not sensitive to any one of the included studies, Figure 4.

Ethical approval: The conducted research is not related to either human or animals use.

\section{Publication bias analysis}

The publications bias was evaluated by a funnel plot and Egger's line regression test. The funnel plot was asymmetrical at the bottom which demonstrated obvious publication bias (Figure 5). However, the Egger's line regression test indicated no publications bias $(\mathrm{t}=1.45$, $\mathrm{p}=0.17$ ).

\section{Discussion}

Ulcerative colitis is a chronic nonspecific inflammatory disease of the colon and rectum whose etiology is still unclear [30,31]. The lesion are usually confined to the mucosa and submucosa of the large intestine. Most lesions are located in the sigmoid colon and rectum, but can also extend to the descending colon or even the whole colon $[32,33]$. The course of the disease is long and often recurs. This disease occurs at any age, but the most common 
Table 2: Sensitivity analysis of SMD by omitting each of the included publications.

\begin{tabular}{|c|c|c|c|}
\hline \multirow[t]{2}{*}{ Study omitted } & \multirow{2}{*}{$\begin{array}{l}\text { Estimate } \\
\text { SMD }\end{array}$} & \multicolumn{2}{|l|}{$95 \% \mathrm{Cl}$} \\
\hline & & Lower limit & Upper limit \\
\hline Danese (2005) & 1.21 & 0.88 & 1.54 \\
\hline Drzewoski J (2006) | & 1.20 & 0.88 & 1.53 \\
\hline Jiang Y (2010) & 1.19 & 0.85 & 1.54 \\
\hline Akbulut S (2010) & 1.22 & 0.905 & 1.56 \\
\hline Chen ML (2012) & 1.24 & 0.92 & 1.57 \\
\hline Sun J (2012) & 1.23 & 0.91 & 1.56 \\
\hline Ni Z (2013) & 1.22 & 0.89 & 1.55 \\
\hline Wang JJ (2014) & 1.23 & 0.90 & 1.56 \\
\hline Liu SL (2014) & 1.22 & 0.90 & 1.55 \\
\hline Ju HY (2014) & 1.12 & 0.82 & 1.42 \\
\hline Dnauta (2014) & 1.26 & 0.942 & 1.58 \\
\hline Chen SW (2015) & 1.09 & 0.82 & 1.36 \\
\hline Zhou XJ (2015) & 1.14 & 0.83 & 1.45 \\
\hline Yang J (2016) & 1.19 & 0.86 & 1.51 \\
\hline Zhuo XJ (2016) & 1.13 & 0.82 & 1.441 \\
\hline Xue XY (2017) & 1.23 & 0.89 & 1.561 \\
\hline Zheng SZ (2017) & 1.24 & 0.91 & 1.58 \\
\hline Liu C (2018) & 1.22 & 0.89 & 1.551 \\
\hline Combined & 1.20 & 0.89 & 1.511 \\
\hline
\end{tabular}

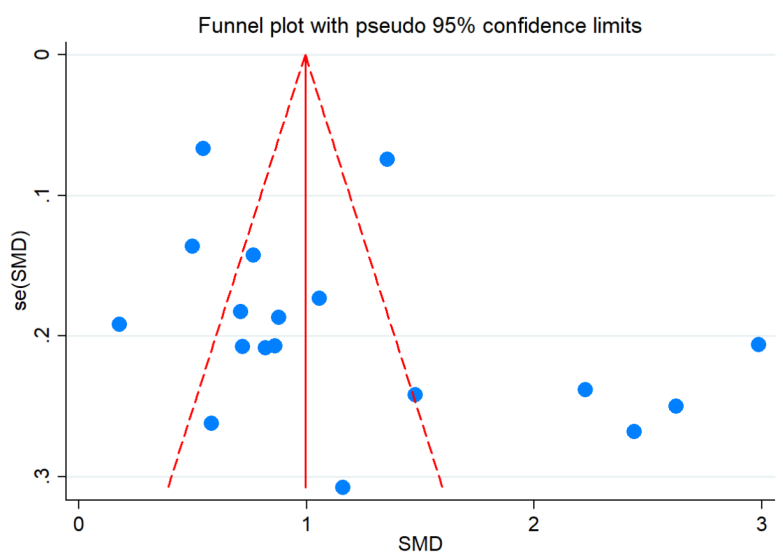

Figure 5: Funnel plot of correlation between serum homocysteine levels and ulcerative colitis. The solid dots represent each included study. is 20-30 years old [34, 35]. The etiology of ulcerative colitis is still unknown. However, most studies believe that psychological factors play an important role in the occurrence and development of ulcerative colitis [36, 37]. Previously publications demonstrated that depression or anxiety was significantly improved after colectomy $[38,39]$. Other studies showed that ulcerative colitis is an autoimmune disease [40, 41].

Homocysteine is a non-proteinogenic $\alpha$-amino acid. It is a homologue of the amino acid cysteine, differing by an additional methylene bridge (-CH2-). It is biosynthesized from methionine by the removal of its terminal $\mathrm{C}^{\varepsilon}$ methyl group. Several studies have discussed the correlation between the serum homocysteine concentration and ulcerative colitis risk, and most of the publication found that the serum homocysteine was elevated in UC patients compared to healthy controls $[10,11]$. However, other studies showed there was no statistical difference of serum Hcy concentration between UC groups and healthy controls [22]. Therefore, we performed this meta-analysis by pooling all the published data relevant to serum homocysteine concentration and ulcerative colitis in order to further evaluate their correlations and potential diagnostic performance as serological biomarker.

In the present meta-analysis, we included eighteen case-control studies published from 2005 to 2018. The pooled data indicated that the serum Hcy levels in UC groups were significantly higher than that of healthy controls $(14.01 \pm 2.76$ vs $10.31 \pm 1.59 \mu \mathrm{mol} / \mathrm{L}, \mathrm{p}<0.05)$. This indicates that Hcy may play an important role in UC development and may be used as serological biomarker for UC diagnosis.

However, there were several limitations of the present meta-analysis: (i) significant statistical heterogeneity across the included studies, (ii) only studies published in English or Chinese were screened and included, and (ii) the general quality of the original publications was low.

In conclusion, increased serum Hcy levels were associated with the increased risk of UC. However, all the studies included were case-control studies, which can not reveal the causal relationship between Hcy level and UC. Therefore, more prospective cohort or basic studies relevant to Hcy and UC are needed to further evaluate the their correlation or provide more precise evidence.

Conflict of interest: Authors state no conflict of interest 


\section{References}

1. Veyrat-Durebex C, Blasco H, Crinier J, Vayne C, Emond P, Labarthe F, et al. [Investigation of hyperhomocysteinemia]. Ann Biol Clin (Paris) 2013;71:517-25.

2. Eldibany MM, Caprini JA. Hyperhomocysteinemia and thrombosis: an overview. Arch Pathol Lab Med 2007;131:87284.

3. Gatt A, Makris M. Hyperhomocysteinemia and venous thrombosis. Semin Hematol 2007;44:70-6.

4. Morris MS. Homocysteine and Alzheimer's disease. Lancet Neurol 2003;2:425-8.

5. Smith AD, Smith SM, de Jager CA, Whitbread P, Johnston C, Agacinski $\mathrm{G}$, et al. Homocysteine-lowering by B vitamins slows the rate of accelerated brain atrophy in mild cognitive impairment: a randomized controlled trial. PLoS One 2010;5:e12244.

6. Sawka AM, Ray JG, Yi Q, Josse RG, Lonn E. Randomized clinical trial of homocysteine level lowering therapy and fractures. Arch Intern Med 2007;167:2136-9.

7. Dhonukshe-Rutten RA, Pluijm SM, de Groot LC, Lips P, Smit JH, van Staveren WA. Homocysteine and vitamin B12 status relate to bone turnover markers, broadband ultrasound attenuation, and fractures in healthy elderly people. J Bone Miner Res 2005;20:921-9.

8. Kuang ZM, Wang Y, Feng SJ, Jiang L, Cheng WL. Association Between Plasma Homocysteine and Microalbuminuria in Untreated Patients with Essential Hypertension: a Case-Control Study. Kidney Blood Press Res 2017;42:1303-1311.

9. Cho EH, Kim EH, Kim WG, Jeong EH, Koh EH, Lee WJ, et al. Homocysteine as a risk factor for development of microalbuminuria in type 2 diabetes. Korean Diabetes J 2010;34:200-6.

10. Danese S, Sgambato A, Papa A, Scaldaferri F, Pola R, Sans M, Lovecchio M, Gasbarrini G, Cittadini A, Gasbarrini A. Homocysteine triggers mucosal microvascular activation in inflammatory bowel disease. Am J Gastroenterol 2005;100:886-95.

11. Drzewoski J, Gasiorowska A, Matecka-Panas E, Bald E, Czupryniak L. Plasma total homocysteine in the active stage of ulcerative colitis. J Gastroenterol Hepatol 2006;21:739-43.

12. Zintzaras E. Genetic variants of homocysteine/folate metabolism pathway and risk of inflammatory bowel disease: a synopsis and meta-analysis of genetic association studies. Biomarkers 2010;15:69-79.

13. Stang A. Critical evaluation of the Newcastle-Ottawa scale for the assessment of the quality of nonrandomized studies in meta-analyses. Eur J Epidemiol 2010;25:603-5.

14. Yi J, Jie Z, Chang-long XU, Shu-guang C, Li-miao L, Yuan L, et al. The relationship of methylenetetrahydrofolate reductase G1793A gene polymorphism, hyperhomocysteinaemia and ulcerative colitis. CHINESE JOURNAL OF INTERNAL MEDICINE 2010;49:675-679.

15. Akbulut S, Altiparmak E, Topal F, Ozaslan E, Kucukazman M, Yonem 0 . Increased levels of homocysteine in patients with ulcerative colitis. World J Gastroenterol 2010;16:2411-6.

16. Chen M, Mei Q, Xu J, Lu C, Fang H, Liu X. Detection of melatonin and homocysteine simultaneously in ulcerative colitis. Clin Chim Acta 2012;413:30-3.
17. Jing S, Guangbo Z. Detection and clinical significance of serum homocysteine in ulcerative colitis. Chin J Lab Pathol 2012;4:236-238.

18. Zhen N. Analysis of serum homocysteine level in patients with ulcerative colitis. International Journal of Laboratory Medicine 2013;34:727-728.

19. Jingjun W. Detection of serum homocysteine in patients with ulcerative colitis and its clinical significance. The Journal of Medical Theory and Practice 2014;27:2773-2774.

20. Shuli L, Guiqin C, Liqin G. Diagnostic significance of serum homocysteine and anti-neutrophil cytoplasmic antibody in ulcerative colitis. Chongqing Medicine 2014:3069-3070.

21. Hongyan J, Yang B. Association of genetic polymorphism of homocysteine and metabolic enzymes, folic acid and vitamin B12 with ulcerative colitis. Chinese Journal of Gerontology 2014:2113-2115.

22. Owczarek D, Cibor D, Sałapa K, Jurczyszyn A, Mach T. Homocysteine in patients with inflammatory bowel diseases. Przegl Lek 2014;71:189-92.

23. Shaowen C, Donghai W, Mingzhu J. Association of genetic polymorphism of homocysteine and metabolic enzymes, folic acid, vitamin B12 in patients with ulcerative colitis. Chinese Journal of Modern Drug Application 2015;9:32-33.

24. Xujun Z, Xiujun G. Correlation of serum homocysteine with folic acid and vitamin B_12 in patients with ulcerative colitis. Beijing Medical Journal 2015;37:175-176.

25. Jian Y, Xueqing C. Early diagnosis value of homocysteine and D-dimmer in patients with ulcerative colitis. J Trop Med 2016;16:448-451.

26. Xianjin Z, Chuquan H, Shen Z. Value of serum homocysteine and inflammatory factor in the diagnostis of ulcerative colitis. Journal of Bethune Military Medical College 2016;14:145-147.

27. Xioangyan X, Changlin Z, Lianhua P, Shaozhen H, Weixuan L. Serum homocysteine, folic acid and vitamin B12 in ulcerative colitis. Laboratory Medicine and Clinic 2017;14:435-436.

28. Zheng S, Yang W, Wu C, Sun L, Lin D, Lin X, et al. Association of ulcerative colitis with transcobalamin II gene polymorphisms and serum homocysteine, vitamin B12, and folate levels in Chinese patients. Immunogenetics 2017;69:421-428.

29. Cheng L, Tongbo Y, Zhenjuan Z. Value research of serum homocysteine and anti-neutrophil cytoplasmic antibodies in the diagnosis of ulcerative colitis. China Practical Medical 2018;13:19-21.

30. Hanauer SB. Update on the etiology, pathogenesis and diagnosis of ulcerative colitis. Nat Clin Pract Gastroenterol Hepatol 2004;1:26-31.

31. Sartor RB. Current concepts of the etiology and pathogenesis of ulcerative colitis and Crohn's disease. Gastroenterol Clin North Am 1995;24:475-507.

32. Utsumi Y, Wakasa H, Abe M. [Morphologic features of ulcerative colitis]. Nihon Rinsho 1999;57:2426-31.

33. Gore RM, Balthazar EJ, Ghahremani GG, Miller FH. CT features of ulcerative colitis and Crohn's disease. AJR Am J Roentgenol 1996;167:3-15.

34. Feuerstein JD, Cheifetz AS. Ulcerative colitis: epidemiology, diagnosis, and management. Mayo Clin Proc 2014;89:1553-63.

35. da SBC, Lyra AC, Rocha R, Santana GO. Epidemiology, demographic characteristics and prognostic predictors of ulcerative colitis. World J Gastroenterol 2014;20:9458-67. 
36. Barreiro-de AM, Marín-Jiménez I, Panadero A, Guardiola J, Cañas M, Gobbo MM, Modino Y, et al. Recommendations of the Spanish Working Group on Crohn's Disease and Ulcerative Colitis (GETECCU) and the Association of Crohn's Disease and Ulcerative Colitis Patients (ACCU) in the management of psychological problems in Inflammatory Bowel Disease patients. Gastroenterol Hepatol 2018;41:118-127.

37. O'Connor JF. Psychological considerations in ulcerative colitis. N Y State J Med 1968;68:1055-65.

38. Vlachos II, Barbatis C, Tsopanomichalou M, Abou-Assabeh L, Goumas K, Ginieri-Coccossis M, et al. Correlation between depression, anxiety, and polymorphonuclear cells' resilience in ulcerative colitis: the mediating role of heat shock protein 70 . BMC Gastroenterol 2014;14:77.

39. Ananthakrishnan AN, Gainer VS, Cai T, Perez RG, Cheng SC, Savova G, et al. Similar risk of depression and anxiety following surgery or hospitalization for Crohn's disease and ulcerative colitis. Am J Gastroenterol 2013;108:594-601.

40. Guinet-Charpentier C, Champigneulle J, Williet N, PeyrinBiroulet L, Morali A. The association of autoimmune diseases with pediatric ulcerative colitis does not influence its disease course. Scand J Gastroenterol 2016;51:33-40.

41. Modebe 0 . Autoimmune thyroid disease with ulcerative colitis. Postgrad Med J 1986;62:475-6. 